\title{
O trabalho cotidiano dos catadores no urbano periférico da cidade de Santa Maria, RS: caso do bairro Camobi
}

\author{
The daily work of scavengers in the urban periphery of the city of Santa Maria, RS: \\ Case Camobi neighborhood
}

\author{
Sandra Ana Bolfe ${ }^{* 1}$, Janete Webler Cancelier ${ }^{2}$, Thaís Silveira Alves ${ }^{3}$, Valquíria Ines Ferla Stefani ${ }^{4}$ \\ 1. Professora Departamento de Geociências, Curso de Geografia, UFSM, Santa Maria, Brasil \\ ${ }^{2}$ Doutoranda em Geografia, UFSM, Santa Maria, Brasil \\ ${ }^{3}$ Graduação Geografia, UFSM, Santa Maria, Brasil \\ 4. GraduaçãoTecnólogo em Gestão de Cooperativas, UFSM, Santa Maria, Brasil
}

\begin{abstract}
Resumo
A temática que gira em torno dos catadores de material reciclável toma vigor em nossa sociedade e traz uma diversidade de questões que exigem respostas na compreensão das relações de trabalho e de produção desses trabalhadores que estão na base da indústria da reciclagem. Eles são, a cada dia, mais numerosos na cidade e sua presença (des) agrada os mais diversos órgãos e a sociedade como um todo. O local de estudo é o bairro Camobi, cidade de Santa Maria, RS o qual se situa no urbano periférico mais distante do bairro Centro. Neste texto, abordam-se o cotidiano do trabalho dos catadores com vistas àqueles que buscam, nesse trabalho, a fonte de sua sobrevizência, como também outras formas de emprego e renda. Neste sentido, o objetivo deste artigo é compreender o trabalho cotidiano dos trabalhadores "sobrantes" do urbano periférico da cidade de Santa Maria, RS, especialmente os que trabalham na coleta de material reciclável no e do bairro Camobi. Também se apresenta o espaço de vida e de trabalho da família desses catadores que têm, na "catação/pedição", expectativas de encontrar na rua bens para sua sobrevizência. São relações construídas pelos catadores que criam laços territoriais que lhes favorecem formas de sustentar necessidades básicas da vida. O trabalho cotidiano dos catadores representa um embate ao poder público, às empresas e à sociedade, numa relação de (in) visibilidade no mundo do trabalho onde essas pessoas lutam pelos direitos de sua cidadania.
\end{abstract}

Palavras-chave: trabalhadores catadores - periférico urbano - material reciclável - trabalho cotidiano

\begin{abstract}
The theme that revolves around the waste pickers takes place in our society and brings a variety of questions that require answers in the understanding of labor relations and production of these workers that are the basis for the recycling industry. They are every day more numerous in the city and their presence (dis) like the various organs and society as a whole. The study site is the Camobi district, city of Santa Maria, RS which is located in the urban periphery farther from the Centro neighborhood. In this text, addressing the daily work of scavengers views with those who seek, in this work, the source of their survival, as well as other forms of employment and income. In this sense, the aim of this paper is to understand the daily work of employees "spare "the urban periphery of the city of Santa Maria, RS, especially those who work in the collection of recyclable material in and Camobi neighborhood. Also presents the living space and working family who have these scavengers in "grooming / pedição " expectations to meet on the street means of survival . Relationships are built by scavengers who create territorial ties that favor them ways to sustain basic needs of life. The daily work of scavengers is a clash with the public authorities, businesses and society, in a ratio of (in) visibility in the working world where these people fighting for the rights of citizenship.
\end{abstract}

Keywords: collectors workers - urban peripheral - recyclable material - daily work

*sabolfe@hotmail.com.br

Recebido: 08/04/2014 Aceito: 08/04/2014 


\section{Introdução}

$\mathrm{O}$ direito ao trabalho é um dos direitos fundamentais dos seres humanos. No Brasil este direito é garantido pela Constituição Brasileira, assim como os direitos sociais, os direitos humanos e os direitos culturais. Porém, o desemprego ainda é um desafio para os governos, que têm visto nas políticas públicas uma alternativa em curto prazo de garantir o mínimo, para a sobrevivência de um grande número de pessoas que vivem entre a pobreza e a miséria. O desemprego é, também, responsável por uma grande parcela de problemas sociais e contribui para que as pessoas não consigam uma verdadeira integração na sociedade. Neste cenário, o lixo e a atividade de catador de materiais recicláveis, surgem como alternativa pela busca da sobrevivência nos centros e periferias urbanas. O lixo, que contém os materiais recicláveis, e mesmo alimentos descartados são encontrados de forma cada vez mais abundante nas ruas, tornando-se fonte de recursos que garantem a sobrevivência de famílias inteiras.

A pesquisa ${ }^{1}$ iniciou pela busca de pessoas que trabalham como catadores de material reciclável no bairro Camobi, cidade de Santa Maria, RS, os quais se chamam trabalhadores "sobrantes" pelo capital. Este termo ressignifica o mundo do trabalho, uma vez que a "matéria segunda" (Rodrigues, 1998), o lixo, torna-se mercadoria apropriada pelo capital na exploração da força de trabalho desses trabalhadores. A catação, outro significado para a coleta do "lixo", que não é lixo, tem organizado em praticamente todas as cidades brasileiras um novo significado na divisão social e territorial do trabalho chamado informal.

Conforme Santos (2001, p.144):

No fundo, a questão da escassez aparece outra vez como central. Os 'de baixo' não dispõem de meios (materiais e outros) para participar plenamente da cultura moderna de massas. Mas sua cultura, por ser baseada no território, no trabalho e no cotidiano, ganha a força necessária para deformar, ali mesmo, o impacto da cultura de massas. Gente junta cria cultura e, paralelamente, cria uma economia territorializada, uma cultura territorializada, um discurso territorializado, uma política territorializada.

Grupos de pessoas ou mesmo individualmente estão distribuídos pelo espaço urbano, territorializando-se na busca de mercadoria, aqui entendida como matéria segunda, ou seja, o material reciclável, que passou a ter (re)valorização de uso e de troca. Diz respeito à

1 A pesquisa é parte do projeto de extensão - FIEX financiado pela Universidade Federal de Santa Maria, do qual fazem parte um grupo de pesquisadores, alunos de graduação e pós-graduação. matéria segunda que retorna ao ciclo produtivo (ou cadeia produtiva), em que o setor mais beneficiado é o da indústria de reciclagem. A partir desse setor, outros (re)estruturam-se para garantir a (re)produção do capital. São setores que vão desde a pesquisa científica e tecnológica, da informação e comunicação, bem como dos intermediários ou atravessadores.

Este material tornou-se mercadoria valiosa para a indústria de reciclagem, inserindo novos valores no trato das mercadorias, ou seja, o destino final das embalagens, após o uso do produto. A reciclagem, processo de reutilização da matéria segunda, conscientiza, por assim dizer, novas relações e valores que compreendem a ideologia de um futuro (in)sustentável para o planeta Terra.

No Brasil, um dado importante aponta para o avanço da coleta seletiva com inclusão social de catadores. A Política Nacional de Resíduos Sólidos - PNRS - buscou durante 20 anos, no Legislativo, a aprovação de um plano para a coleta seletiva nos municípios brasileiros, os quais, em 2010, foram apenas $18 \%$ do total de 5.565. A última pesquisa dessa política foi feita em 2008 e verificou 653 municípios que realizam a coleta seletiva em parceria com os catadores, pois está longe de acontecer uma "coleta seletiva sustentável e efetiva" (BESEN, 2012, p.56).

Nesse contexto, o urbano periférico da cidade de Santa Maria traduz essas relações de trabalho com os materiais descartáveis, recicláveis, reaproveitáveis. A matéria segunda descartada no lixo em frente às residências, ao comércio, às indústrias passou a ter um valor monetário vinculado à indústria de reciclagem no mundo todo.

A vida cotidiana dos trabalhadores na coleta de material reciclável representa para a nossa sociedade a dualidade que existe na relação sociedade e natureza. De um lado, ao coexistir com indústria capitalista, o trabalho dos catadores possui uma relação de servidão, ou seja, de exploração da sua força vital, pois a eles não são garantidos os mínimos direitos de vida e de trabalho. Por outro lado, estão os intermináveis discursos sobre a natureza, vista aqui como matéria segunda, o lixo descartado, e tido como mercadoria, pois tem seu valor de uso e de troca ditados pela indústria de reciclagem responsável pela degradação do meio ambiente.

Nesse processo, surge o ciclo dessa mercadoria, a qual percorre um longínquo e complexo caminho que inicia pelo descarte do material reciclável - mercadoria - gerando disputa acirrada entre os trabalhadores que territorializam-se pelos lugares da cidade. $\mathrm{O}$ tempo e o espaço desses trabalhadores têm compreendido outras relações que vão além da coleta do material reciclável chegando a uma relação de "pedintes", onde aparecem especialmente mulheres e crianças.

O objetivo deste artigo é compreender o trabalho cotidiano dos trabalhadores "sobrantes" do urbano periférico da cidade de Santa Maria, especialmente os que trabalham na coleta de material reciclável no/do bairro Camobi. O trabalho cotidiano dos catadores inscreve-se neste artigo pelas suas condições de vida e de 


\begin{tabular}{c|c|c|c}
\hline $\begin{array}{c}\text { Identificação } \\
\text { do catador }\end{array}$ & Idade & Local Moradia & $\begin{array}{c}\text { Tempo Moradia } \\
\text { (anos) }\end{array}$ \\
\hline 1 & +60 & Vila Maringá & - \\
\hline 2 & 75 & V. Jardim & 36 \\
\hline 3 & 56 & Vila Maringá & 40 \\
\hline 4 & 34 & Vila Maringá & 7 \\
\hline 5 & 18 & Vila Maringá & 8 \\
\hline 6 & 42 & Vila progresso & 10 \\
\hline 7 & 40 & Vila Maringá & 7 \\
\hline 8 & 24 & Vila Maringá & 5 \\
\hline 9 & 44 & Vila Maringá & 8 \\
\hline 10 & 73 & Vila Maringá & 6 \\
\hline 11 & 23 & Vila Maringá & 7 \\
\hline 12 & 45 & Vila Maringá & 16 \\
\hline 13 & 16 & Vila Maringá & 8 \\
\hline 14 & 15 & Vila Maringá & 8 \\
\hline 15 & 48 & Vila Maringá & 5 \\
\hline 16 & 56 & Beco do beijo & 12 \\
\hline 17 & 33 & Vila Maringá & 10 \\
\hline
\end{tabular}

Figura 1. Situação dos Catadores entrevistados no bairro Camobi, cidade de Santa Maria, RS.

Fonte: Trabalho de Campo, de agosto a novembro de 2013

trabalho; pela apropriação dos espaços e tempos diante das relações de trabalho e dos meios e instrumentos pertinentes as forma de trabalho e renda advindos da catação do material reciclável.

O estudo possibilita uma visão geral sobre a desigualdade, a segregação sócio espacial, as dificuldades diárias dos trabalhadores e da luta pela sobrevivência. Através da análise bibliográfica sobre sujeito, identidade, e minorias podem-se compreender a importância da construção de sujeitos e sua emancipação.

\section{Procedimentos Metodológicos}

\section{1 Área de estudo e sujeitos sociais investigados}

Este artigo utiliza como método de pesquisa o paradigma qualitativo ${ }^{2}$, que visa conforme Godoy (1995, p.58) “... compreender os fenômenos segundo a perspectiva dos sujeitos, ou seja, dos participantes da situação em estudo". Considera o ambiente como fonte direta dos dados e o pesquisador como instrumento chave. Nesse sentido, Godoy (1995, p.62) afirma que o pesquisador deve aprender a usar a si próprio como "instrumento mais confiável de observação, seleção, análise e interpretação dos dados coletados". Desta forma, serão analisados e avaliados os comportamentos e, as características específicas do grupo em estudo.

Para Cooper (2003, p.133) "as descobertas ficam mais

2 Por ser uma abordagem mais interpretativa que se propõe traduzir e expressar o fenômeno estudado se constitui em um trabalho laborioso, visto que é necessário registrar as informações, coletar dados, organizá-los e fazer as análises. (MATOS; PESSÔA, 2009, p.282). fáceis se o pesquisador puder analisar casos que forneçam informações especiais." Os dados analisados, é o resultado do projeto de extensão do grupo de estudos "O cotidiano dos catadores "sobrantes" no urbano periférico da cidade de Santa Maria, RS: caso do bairro Camobi".

Entre os instrumentos utilizados para obtenção de dados e de informações estão as entrevistas semi-estruturadas, as pesquisas bibliográficas, a sistematização e as análises. O público-alvo desta pesquisa são catadores de rua, os quais não participam de associações ou cooperativas.

Para a coleta dos dados, realizaram-se entrevistas com 17 trabalhadores, conforme evidenciado na figura 1.

Foram também realizados dois encontros com vários trabalhadores envolvidos na atividade de coleta de materiais recicláveis. Os encontros ocorreram entre os dias 02 e 25 de junho de 2013, e tiveram a duração de, aproximadamente, 60 minutos cada.

As entrevistas ocorreram de forma direta com questões abertas e fechadas e seguiram um roteiro determinado de questões as quais procuravam acima de tudo conhecer o perfil sócio econômico, os locais de moradia, os meios e instrumentos de trabalho, as condições de trabalho e renda gerada com a atividade de catação, bem como, visava conhecer a pretensão deste trabalhador em participar de uma possível cooperativa ou associação de separação de material reciclável.

As discussões acerca da renda e trabalho são resultantes das análises do universo dos trabalhadores catadores entrevistados. Neste estudo não se busca uma representatividade estatística da amostra, mas sim uma abrangência capaz de dar conta da diversidade de relações de trabalho e produção onde o catador se encontra na base da indústria de reciclagem. 


\subsection{Local e sujeitos}

Grande parte dos trabalhadores investigados foi entrevistada no local de suas moradias, na Vila Maringá (Bairro Diácono João Luiz Pozzobom), Beco do Beijo e Vila Progresso (bairro Camobi). É importante salientar que todos realizam coleta de materiais recicláveis no bairro Camobi, cidade de Santa Maria, RS, conforme mostra a figura 2.

Optou-se por encontrar os catadores para a entrevista no local de sua moradia, pois houve dificuldade de fazer a entrevista na rua, seu local de trabalho, procurando-os em dias e horários fora do trabalho na coleta, o qual se realizava principalmente no turno da manhã, na segunda-feira, quarta-feira e sexta-feira, dias em que passava o caminhão de coleta do lixo no bairro Camobi. Os bairros da periferia da cidade de Santa Maria têm coleta de lixo nesses três dias, enquanto na área central ocorrem todos os dias, em locais específicos depositados em contêineres ocasionando polêmicas quanto à manutenção e solução para a questão do lixo na/da cidade.

\section{Resultados e Discussões}

\subsection{Trabalho, identidade e direitos sociais}

Para a conquista da independência, um dos pressupostos básicos é o indivíduo estar inserido no mercado de trabalho ${ }^{3}$, realizando uma atividade formal, com benefícios garantidos, segurança e permitindo exercer a sua cidadania e sua inclusão social. Segundo o IBGE - Instituto Brasileiro de Geografia e Estatística, cerca de $5,2 \%$ de brasileiros estão desocupados atualmente. Isso significa dizer que em torno de 1,3 milhão de pessoas no Brasil não têm acesso ao direito do trabalho. Pode-se dizer, ainda, que todas essas pessoas estão desconectadas, pois para estar conectado com a sociedade atual,

3 O IBGE conceitua trabalho como a ocupação econômica remunerada em dinheiro, produtos ou outras formas não monetárias, ou a ocupação econômica sem remuneração, exercida pelo menos durante 15 horas na semana, em ajuda a membro da unidade domiciliar em sua atividade econômica, ou a instituições religiosas beneficentes ou em cooperativismo, como aprendiz ou estagiário. (IBGE, 2013).

\section{MAPA DE LOCALIZAÇÃO DA CONCENTRAÇÃO DE TRABALHADORES NA COLETA DE MATERIAIS RECICLÁVEIS NOS BAIRROS CAMOBI E DIÁCONO JOÃO LUIZ POZZOBON, SANTA MARIA/RS}

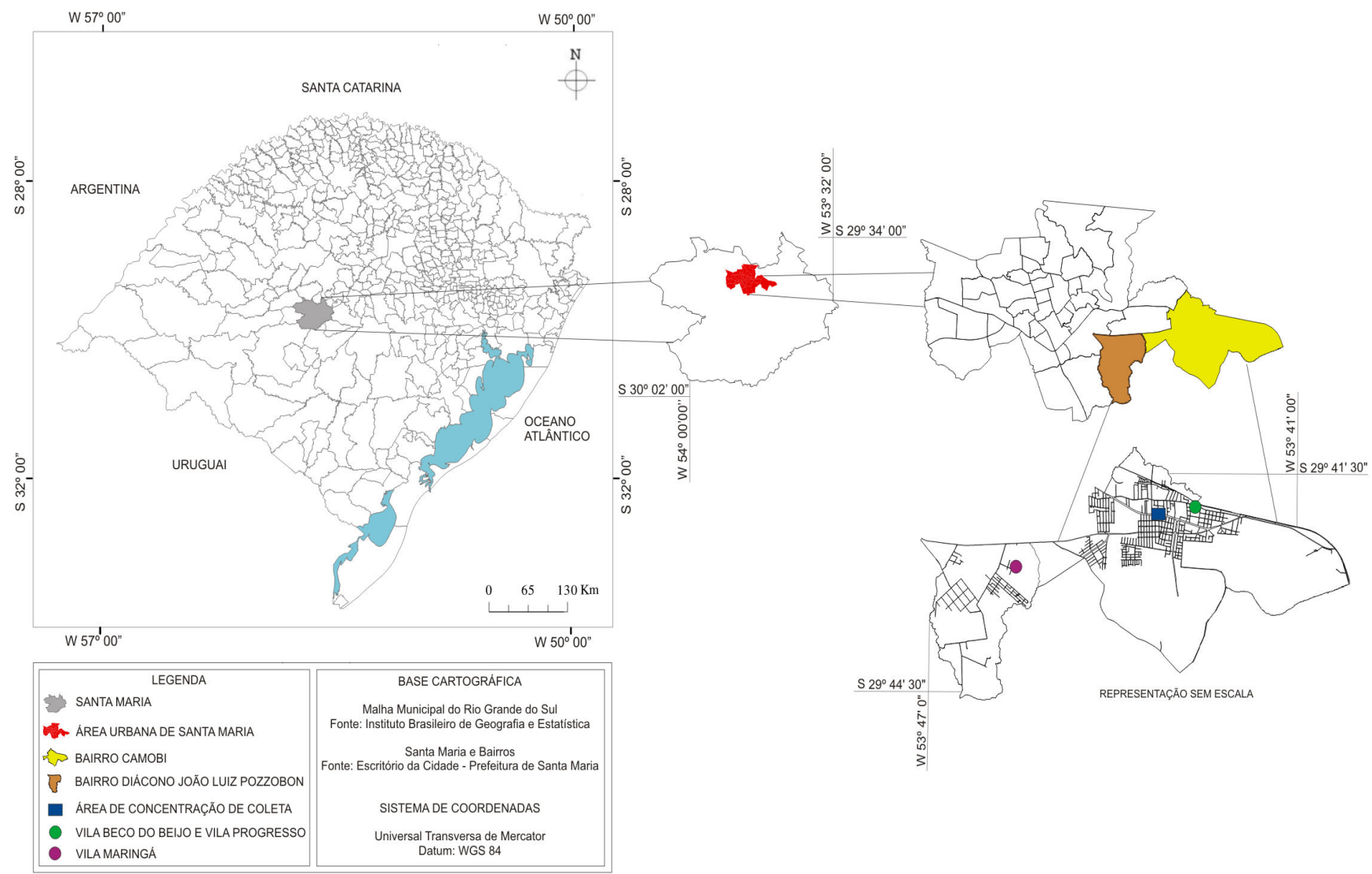

Figura 2. Mapa da localização de trabalhadores na coleta de materiais recicláveis, Bairro Camobi e Bairro Diácono Jão Luiz Pozzobom, Santa Maria, RS

Fonte: Trabalho de campo, 2013 
capitalista e globalizada, o sujeito precisa obrigatoriamente estar inserido no mercado de trabalho/consumo e produzindo, caso contrário é compreendido e visto com desprezo.

A falta de emprego, de qualificação e a baixa escolaridade, aliadas a falta de fiscalização e a necessidade de sobrevivência promovem o mercado informal, onde os trabalhadores são submetidos a condições degradantes, jornadas de trabalho abusivas, sem segurança, sem benefícios e sem garantias, enfim sem nenhum direito. É neste cenário, que os trabalhadores da coleta de materiais recicláveis estão inseridos.

A coleta de material reciclável é uma atividade informal e que está em ascensão, pois as pessoas, de modo geral, não pensam ou se questionam para onde vai ou qual o destino de tantas "coisas" que jogamos fora e têm a ilusão de que o lixo, após ser descartado, desaparece e que os aterros sanitários são as únicas opções de destino final. Assim como, o lixo descartado sobre o qual não pensamos ou não queremos pensar, os catadores de matérias recicláveis são vistos como anônimos e a sociedade procura não os conhecer e deslegitimar.

Porém, esses trabalhadores, quando entrevistados, mostram estar convencidos de que o trabalho que fazem é de extrema importância para o meio ambiente e para a sociedade, dizendo que se orgulham de tornar o mundo melhor e que gostam do trabalho que realizam e o enxergam como um trabalho de limpeza. No entanto, percebe-se um discurso desconcertado da prática. Fica evidente que a maioria dessas pessoas são iludidas e ludibriadas acreditando que o trabalho que realizam é um trabalho importante para sustentabilidade e não conseguem perceber que são privadas de seus direitos como cidadãos e sujeitos a condições degradantes, sem proteção, expostas ao frio e ao calor, à sujeira e a contaminações e, além disso, por realizarem essa atividade sem nenhum benefício garantido por lei, ainda são excluídas da sociedade. Pois como evidência Canclini (2009, p.66) a desigualdade não é apenas a diferença de classes, mas sim a apropriação desigual de bens materiais e simbólicos. A esse respeito Dallari (1998, p.36) preconiza que:

A cidadania expressa um conjunto de direitos que dá à pessoa a possibilidade de participar ativamente da vida e do governo de seu povo. Quem não tem cidadania está marginalizado ou excluído da vida social e da tomada de decisões, ficando numa posição de inferioridade dentro do grupo social.

Neste contexto, percebe-se que o trabalho dos catadores representa um embate ao poder público, às empresas e à sociedade, numa relação de (in) visibilidade no mundo do trabalho, onde essas pessoas lutam pelos direitos de sua cidadania. A desigualdade e a pobreza a que estão expostos frente a trabalhadores incluídos no mercado formal, os coloca a margem da economia formal.

É preciso reconhecer também, que essas pessoas necessitam urgentemente de políticas públicas capazes de garantir a sua sobrevivência e a permanência de seus filhos na escola. Compreende-se que as políticas podem não garantir a dependência dos que hoje recebem o benefício, mas é uma possibilidade de emancipação de seus dependentes amanhã. Serve de exemplo o benefício Bolsa Escola que integra o programa Fome Zero.

No que se refere à cidadania ou exclusão Canclini (2009, p.46) aponta que "a cidadania - ou seu contrário: a exclusão - é o resultado da correlação entre os índices de concentração das oportunidades de acesso a outros recursos capacitadores". Neste contexto, o sujeito passa a ser cidadão quando é incluído na sociedade e quando sua diferença não o condena a desigualdade.

Colocar-se no lugar do outro é uma experiência que os seres humanos conhecem, mas é pouco praticada e muitos que o fazem é de maneira a servir seus próprios interesses e não ao coletivo. É mais fácil e confortável apenas entender a dor, o sofrimento das pessoas que estão à margem, simplesmente justificando que são pessoas que não tiveram oportunidades, que nasceram pobres e que continuaram dentro daquele sistema por não existir oportunidades para todos.

Compreender as diferenças e associar o que nos iguala é a proposta de Canclini para uma convivência entre as diferentes pessoas e culturas na busca da integração social, mas sem uma anular a diversidade da outra, de forma a valorizar todos os sujeitos sociais, de modo que possam interagir sem a intenção de impor a sua cultura ou sem ser homogeneizado.

A esse respeito Boaventura de Souza Santos afirma que é preciso um "novo modo de produção de conhecimento" que dê conta dos problemas modernos, permitindo uma sociedade mais justa. E com relação à desigualdade, afirma que os governos se preocupam em mantê-la em um nível tolerável.

No que respeita à desigualdade, a função consiste em manter a desigualdade dentro dos limites que não inviabilizem a integração subordinada, designada de inclusão social pelas políticas estatais. Os direitos sociais e econômicos universais, rendimento mínimo de inserção social e as políticas compensatórias, ("fome-zero, bolsa-escola, abono de família, assistência social) são os mecanismos modernos (muito diferentes entre si) para manter a desigualdade em níveis toleráveis (SANTOS, 2008, p.285) .

Ainda, segundo o autor, esse modelo de regulação social está em crise, pois com as políticas públicas o processo de acumulação capitalista exige das classes populares a integração pelo trabalho e pelo consumo, passando a serem os dois lados da inclusão subordinada. Os programas sociais têm como pressuposto básico, incluir as pessoas que vivem à margem da sociedade garantindo assim os seus direitos e a cidadania. Porém aumentam ainda mais a concentração de renda e de poder nas mãos dos que já tem muito. Existe um para- 
doxo na práxis, pois uma vez que aumentamos o poder de consumo dos mais pobres, também fortalecemos as empresas que produzem e atendem essa demanda.

Para Milton Santos existe uma ambivalência do mundo globalizado, onde a globalização perversa defende um mercado avassalador com o poder de homogeneizar o planeta, mas que na verdade acentua a desigualdade, onde as pessoas que já são ricas se tornam cada vez mais ricas e, as pessoas que já estão à margem não conseguirão uma independência econômica e tampouco seus direitos culturais.

E nesse contexto podemos analisar os catadores de materiais recicláveis, enquanto sujeitos que buscam garantir seus direitos de cidadãos. Mas acima de tudo assegurar sua sobrevivência e na medida do possível estar inserido dentro desta sociedade, que se apresenta de forma eletiva, desigual e fragmentada. Desta forma, este artigo problematiza as discussões a cerca da inclusão dos catadores na economia formal.

\subsection{Lixo e sociedade: uma relação complexa}

O advento da Revolução Industrial, o crescimento da população e a concentração da população urbana podem ser considerados os processos propulsores do progressivo aumento da utilização dos recursos naturais e conseqüentemente da produção de resíduos sólidos.

Segundo o Panorama dos Resíduos sólidos, da Associação Brasileira de Empresas de Limpeza e Resíduos Especiais (Abrelpe) a quantidade de resíduos sólidos coletadas no Brasil em 2012 totalizou 62.730 .096 toneladas, (onde menos de $2 \%$ é reciclado), deste total cada pessoa seria responsável pela produção de $383,2 \mathrm{Kg}$ ao ano. A produção dos resíduos sólidos no período compreendido entre 2011 e 2012 foi maior que a taxa de crescimento da população ${ }^{4}$. Neste contexto, fica evidenciado que o consumo e a geração de resíduos vêm aumentando de forma significativa ao longo dos anos.

$\mathrm{O}$ aperfeiçoamento das técnicas produtivas e os avanços científicos possibilitam que a produção de mercadorias ocorra em larga escala e esteja disponível a população que possua o poder aquisitivo para adquiri-la. E o sistema econômico por sua vez, apropria-se da natureza via progresso tecnológico induzindo a uma homogeneização dos padrões de produção e consumo contraria à sustentabilidade do planeta, que tem por base a diversidade biológica e cultural (LEFF, 2003).

Em seus estudos Rodrigues (1998) salienta que a produção de lixo é tão antiga quanto o processo de ocupação da Terra pelo homem, mas alteraram-se suas características (durabilidade e volume) no processo de desenvolvimento industrial.

A quantidade de lixo acumulada pode estar associada

4 De 2011 a 2012 ocorreu um crescimento de $1.3 \%$ na produção de resíduos sólidos enquanto a taxa de crescimento da população no mesmo período foi de 0,9\%. (ABRELPE, 2013). à cultura material ${ }^{5}$ de uma cidade, pois se pressupõe que a necessidade de produzir implica em quantidades maiores de matéria-prima e energia que são transformadas em produtos (SOBRAL, 1996). A produção de resíduos está diretamente relacionada ao poder aquisitivo, quanto maior o poder aquisitivo de uma determinada sociedade maior será a produção de resíduos.

No Brasil são produzidas 70 mil toneladas de lixo domiciliar ao dia e somente $2 \%$ deste percentual é reciclado. Atualmente, $60 \%$ dos municípios do país possuem alguma iniciativa de coleta seletiva, no entanto, somente $51,4 \%$ do material coletado é matéria orgânica; 13,5\% são plástico; 13,1\% são papel, papelão e tetra pak; 2,9\% são metais; $2,4 \%$ dos resíduos são vidro; e $16,7 \%$ são outros materiais (ABRELPE, 2O13).

Esses dados demonstram que não basta colocar a disposição da população Esses dados demonstram que não basta colocar a disposição da população o serviço da coleta seletiva, faz-se necessário conscientizar e orientar a população no sentido de realizar a separação do material que pode ser reciclado.

Em seus estudos Calderoni (2003, p.253) relata que a reciclagem oferece vários ganhos à sociedade entre eles estão a "economia de matérias primas, de energia, de água, redução dos encargos públicos com o serviço de coleta e limpeza urbana". Ainda enfatiza que mesmo considerando todos os processos e fases no final ainda dá lucro. Mas esse lucro é para quem? Certamente não é para aqueles que estão na base da indústria de reciclagem.

Tanto o lixo como os resíduos são sobras de uma atividade qualquer e o que as caracterizam como lixo ou resíduo depende dos valores sociais, econômicos e ambientais que atribuímos a elas, consubstanciados no ato do descarte (LOGAREZZI, 2004). O que para a maior parte da sociedade é considerado como lixo, para muitos sujeitos sociais no caso, os catadores de rua passa a ser visto como um produto capaz de garantir sua subsistência.

Neste contexto, o catador surge como um sujeito que tira seu sustento do lixo e para isso utiliza várias práticas. Neste artigo de forma específica, analisa-se o catador que realiza a prática da coleta seletiva na rua de forma individual sem estar vinculados a alguma organização.

\subsection{O município de Santa Maria e seu lixo}

Santa Maria possuiu uma população de $262.368 \mathrm{mil}$ habitantes conforme o Censo do IBGE/2011 - RS. Sendo que mais de $95 \%$ desta população vivendo na área urbana.

Conforme dados da Prefeitura Municipal de Santa Maria, os resíduos sólidos urbanos são enviados à Central de Tratamento de Resíduos da Caturrita (CTRC). O empreendimento possui uma área de 24,7 ha. Em 2011 5 A cultura material representa a objetivação das necessidades do ser humano nas suas múltiplas relações com seu universo vivencial, de criar/produzir os insumos, artefatos, instrumentos/tecnologia que dizem respeito às suas experiências cotidianas que povoam e marcam a história (SOBRAL, 1996, p. 21) 
eram enviados diariamente 300 toneladas de resíduo sólido urbano a CTRC, (lixo proveniente da macrorregião), sendo que, a produção diária de Santa Maria equivalia a 170 toneladas. Na cidade de Santa Maria, RS o local reservado para o tratamento do lixo é a Central de Tratamento de Resíduos da Caturrita, situada no distrito de Santo Antão, zona rural do município, distante 8,7 $\mathrm{Km}$ do centro da cidade (Prefeitura Municipal de Santa Maria, 2013).

O volume de lixo enviado a Central de Tratamento aumenta constantemente, sendo que grande parte desse volume poderia ser reciclado. Faz-se necessário encontrar alternativas viáveis procurando diminuir a quantidade de lixo enviado a Central de Tratamento de Resíduos.

E nesse contexto se inserem os catadores de material reciclável de rua, como sujeitos sociais, portadores de história e de identidade, que procuram acima de tudo desenvolver sua atividade e garantir sua sobrevivência. Estes trabalhadores vão à busca da tão procurada mercadoria nos lixos das cidades, visto que determinados materiais possuem valor para a indústria de reciclagem. Em Santa Maria, alguns catadores têm ponto certo de coleta, mas a maioria disputa, no espaço e no tempo, a sorte de encontrar o valioso material reciclável.

Desta forma, os catadores estão distribuídos por toda a cidade, organizam-se espacialmente numa disputa por esses materiais. Aqueles que não estão associados às cooperativas por diferentes motivos organizam-se de forma individual, tendo geralmente um negociador intermediário que recolhe o material coletado em sua residência, ficando assim sujeitos às ofertas desiguais no pagamento. De outra forma os catadores transportam em carroças, o material por longas distâncias diretamente a empresa intermediária à indústria de reciclagem.

Ao cotidiano desses trabalhadores, tem-se a presença numerosa de carroças com tração animal, apresentandose, desse modo, um quadro degradável de tratamento e saúde dos eqüinos.

\subsection{O trabalho cotidiano dos catadores do bairro Camobi, cidade de Santa Maria, RS}

"A vida cotidiana é um conjunto de atividades que caracterizam a reprodução dos homens particulares, os quais, por sua vez, criam a possibilidade da reprodução social" (HELLER, 2004, p.19). Ao cotidiano dos catadores de material reciclável, cabe discutir, neste artigo, as suas relações de trabalho diárias com os lugares de coleta. Nesses se constroem relações de afetividade e pertencimento junto àqueles que lhes garantem o material reciclável à sua sobrevivência numa relação de doações com sentimento de solidariedade. Entre os catadores também existem aqueles que passam pelos lugares apenas em busca da matéria segunda, ou seja, a mercadoria.

Os catadores se inserem nesse ambiente e dele retiram e produzem suas necessidades. Ainda nesse ambiente eles garantem sua reprodução particular, por meio da assimilação das relações sociais que estão hierarquicamente estabelecidas na lógica da vida cotidiana desenvolvendo atividades sem que tenham consciência do processo através do qual os assimilam (HELLER, 2004).

Contrariamente ao que podemos conceber a realidade do trabalho na catação de resíduos recicláveis não é fruto da vontade, e da ação dos próprios trabalhadores. Leal, (2003) em seus estudos relata que esse trabalhador "completa e faz parte de uma engrenagem muita mais ampla e complexa do que podemos imaginar a partir da observação empírica e superficial das atividades e das condições de vida desses trabalhadores".

De acordo ainda com os apontamentos do autor essa conformação é composta por uma série de participantes, que desempenham atividades e papéis dos mais diferenciados, compondo um imenso circuito produtivo, ou a cadeia produtiva ligada à reciclagem, em que o catador de material reciclável ocupa um lugar de importância. Contudo, trabalha em condições precárias, subumanas e não obtém ganho que lhe garante uma sobrevivência digna. O catador participa como elemento base de um processo produtivo ou de uma cadeia produtiva bastante lucrativa, para os outros é claro, que tem como principal atividade o reaproveitamento de materiais que já foram utilizados e descartados e que podem ser reindustrializados e recolocados novamente no mercado para serem consumidos (LEAL, 2003, p.180).

O dia-a-dia do trabalho dos catadores de material reciclável nas ruas das cidades e de Santa Maria ainda não é tratado com visibilidade em termos da própria legalidade de suas relações de trabalho. A conquista dessa profissão exige um direcionamento de processos e custos, muitas vezes sem alcance do trabalhador, pois a renda que lhes cabe não condiz às próprias necessidades básicas da vida.

O cotidiano dos catadores no bairro Camobi representa uma ínfima parcela da população brasileira que vive da catação de material reciclável incluindo-se nesse processo a pedição ou mendicância, numa relação nem sempre digna e isenta de humilhação. Portanto, junto ao trabalho de coleta desse material - mercadoria - têm-se camuflado, no trabalho informal, os meios de sobrevivência de muitas famílias pelas doações solidárias de alimentos e peças de vestuário, entre outros bens. É dessa forma que eles, os pobres, organizam-se e buscam também na solidariedade meios de sobrevivência.

Pesquisas demonstram que a maioria desses trabalhadores são considerados como "sobrantes" do capital, tendo-lhes restado essa única saída. Assim, excluídos/ incluídos da sociedade - e do processo da indústria da reciclagem - eles tornaram-se os "sobrantes" (Burgos, 2008). Mesmo diante de um trabalho tido como à margem da sociedade, os trabalhadores "sobrantes" encontram na cidade um lugar de liberdade pela presença da disponibilidade da descartada "matéria segunda" (RODRIGUES, 1998). 
Estes trabalhadores possuem, no espaço da cidade, os lugares em que a mercadoria - o lixo - pode-lhes garantir a sobrevivência. Ao situarem-se como um grupo de trabalhadores, eles vêem, nas associações e cooperativas, uma possibilidade de melhorias nas condições de trabalho e renda. Mas muitos deles, ao preferirem a busca da "matéria segunda" nas lixeiras da rua, das calçadas e ainda pior, nos depósitos de lixo, representam uma maioria que não se reconhece nesse trabalho e não é reconhecida pela sociedade.

O sentido de alienação desses trabalhadores, aqui, é pensado enquanto pessoas que, por um lado, dizem gostar do que fazem ("eu sou recicladora e não catadora", disse uma das entrevistadas), sendo que, nesse relato, percebeu-se a força de vontade de trabalhar e de ser reconhecido. Durante os diálogos, eles dizem que querem ser valorizados e que a reciclagem é importante para o meio ambiente. Uma das catadoras lembrou uma passeata que participou no centro da cidade sendo o slogan ambiental uma das bandeiras fortes do movimento. " $\mathrm{O}$ homem singular não é pura e simplismente indivíduo, no sentido aludido; nas condições de manipulação social e da alienação, ele se vai fragmentando cada vez mais 'em papéis." (HELLER, 1970, pág.22)

Acredita-se que o interesse do poder público traz consigo uma das facetas para tornar essa atividade fundamental à execução da política ambiental. Ao sentirem-se com essa carga ideológica, os catadores/trabalhadores sobrantes são ainda mais oprimidos pelo sistema capitalista que não lhes deu oportunidade de vida digna.

Além dos catadores não possuírem direitos vinculados ao trabalho, sua situação tende a piorar, com as políticas públicas que varrem da cidade o povo pobre, liberando o espaço da cidade à especulação imobiliária e à privatização dos serviços urbanos $\left(\mathrm{MNCR}^{6}, 2009\right)$.

Esses aspectos demonstram que a segregação sócio espacial é um elemento presente e atuante na vida dos catadores, pois a estes cabe os espaços menos favorecidos em infra-estrutura das cidades. Na busca por uma solução viável o poder público acaba por forçar um deslocamento espacial desta população ampliando a tendência à segregação.

A atuação do Estado na distribuição dos investimentos em infra-estrutura urbana é desigual, ocorrendo uma defasagem de serviços e infra-estrutura entre os bairros. Os recursos privilegiam determinadas áreas em relação a outras. Na necessidade de modernizar determinados espaços o poder público acaba atendendo aos interesses econômicos e segundo Santos (2008, p.308) "aceitando uma ordem de prioridades que privilegia alguns atores, relegando a segundo plano todo o resto agravando a problemática social". Santos ainda enfatiza que enquanto alguns "atores, graças aos recursos públicos, encontram as condições de sua plena realização, os demais, isto é, a maioria, não têm resposta adequada para as suas necessidades essenciais" (2008, p.308).

6 Movimento Nacional dos Catadores de Materiais Recicláveis.
Neste contexto, concorda-se com Vilhaça que o espaço urbano apresenta-se de forma desigual e contraditória. E o "controle do referido espaço ocorre via mecanismos de natureza econômica, política ideológica" (1998, p.335).

Esses fatores associados tendem a acentuar as disparidades entre as sociedades e os espaços por elas ocupadas, ampliando desta forma as segregações sócio espaciais.

A invisibilidade dos catadores no Brasil se concretiza pela ineficiência das políticas públicas, pela falta de dados quantitativos assim como pesquisas que demonstrem a realidade e a situação a que estes sujeitos estão inseridos. Atualmente este sujeito só é reconhecido enquanto categoria profissional quando se encontra vinculado a cooperativas ou associações.

Um avanço considerável para o reconhecimento dos trabalhadores da reciclagem ocorreu no ano de 2002, período em que se deu a inclusão da categoria ocupacional dos catadores de material reciclável na Classificação Brasileira de Ocupações (CBO). A partir desta fase tornou-se possível segundo Dias (2010) obter dados estatísticos dos catadores nas pesquisas domiciliares, sobretudo as realizadas pelo Instituto Brasileiro de Geografia e Estatística (IBGE).

Ainda existe a lei que aprova a profissão de catador e reciclador de papel, o Projeto de Lei 6822/10, do Senado, que regulamenta a profissão de catador de materiais recicláveis e de reciclador de papel. A lei em si não garante as condições do trabalho em todos os seus aspectos. Segundo a reportagem de Nobre (2010).

O texto define o catador como o profissional autônomo ou associado de cooperativa que cata, seleciona e transporta material reciclável nas vias públicas e nos estabelecimentos públicos ou privados para venda ou uso próprio. Já o reciclador é aquele que recicla papel para venda ou uso próprio. Ele pode atuar de forma autônoma ou integrar-se a cooperativa e trabalhar em casa ou em outro local adequado à atividade. Para atuar como catador ou reciclador, o profissional deverá registrar-se na Superintendência Regional do Trabalho e Emprego de sua cidade. Esse registro será feito mediante a apresentação do documento de identidade, do título de eleitor e do certificado de reservista militar.

No entanto, em notícia a Rede Brasil Atual, publicado 10/01/2012, a presidenta Dilma vetou o projeto de Lei por não ter sido apoiado pelo Movimento Nacional dos Catadores de Materiais Recicláveis (MNCR), devido a dificultar o trabalho e não evitar a exploração dos catadores. A Comissão Nacional do MNCR sugere que seja regulamentada a lei de seguridade social, lei de iniciativa popular № $05 / 2011$ que inclui os catadores como segurados especiais da previdência social.

De acordo com o projeto de Lei PLS 279/2011 (de autoria do Senador Rodrigo Rollemberg - PSB-DF) ao ser enquadrado como segurado especial, esse trabalhador poderá contribuir com apenas 2,3\% de seu faturamento bruto anual e ter direito aos benefícios do 
Instituto Nacional de Seguridade Social (INSS), como aposentadoria e pensão. Essa alíquota de contribuição se justificaria de acordo com o Senador pelo fato de que cerca de 500 mil brasileiros trabalham nessa atividade, a maioria informalmente. E que na média os catadores de lixo recebem por dia de trabalho entre $\mathrm{R} \$ 2$ e $\mathrm{R} \$ 5$, o que justifica, segundo ele, a redução da alíquota de contribuição para a categoria. A medida, ressaltou, favorecerá maior número de inclusão previdenciária e o exercício da cidadania por parte desses trabalhadores.

Os estudos têm caracterizado esses trabalhadores como de baixa renda pela ocupação e posição social associadas aos rendimentos obtidos, no que diz respeito ao capital humano:

(...) que reflete diretamente nas habilidades individuais laborais adquiridas e aos aspectos de qualificação profissional, sendo o nível de instrução escolar um elemento importante para compreender o quadro de desigualdade e pobreza neste setor profissional. Os rendimentos também estão associados a fatores regionais, relações de gênero, raça, faixa etária (...) SANTOS, 2013, p.289).

No caso do público entrevistado, a escolaridade é baixa tendo-se nove catadores com ensino fundamental incompleto e três analfabetos.

Outra presença importante desse trabalho, ao qual a pesquisa chama frequentemente de "catação" é da presença mãe e da criança numa relação de "pedição", que ocorre oportunamente durante a coleta de material reciclável, pela venda de produtos, como frutas (melancia, laranja). O trabalho infantil é muito presente, camuflando-se na companhia da família.

No cotidiano, vê-se também a presença frequente dos equinos que são utilizados para conduzir as carroças e o mau tratamento dado a esses animais, especialmente, a alimentação, as doenças e os maus tratos.

Muito além dessa relação com os animais de tração, está a própria família que o utiliza como meio de trabalho e de transporte. É frequente a presença de crianças menores de idade, representando o trabalho infantil, assim, como de jovens e adolescentes conduzindo as carroças nas ruas da cidade. No interior do bairro, onde não seriam vigiados são muito recorrentes os menores de idade conduzindo as carroças com tração animal. E, no bairro Camobi, ainda é mais problemático, pois se localiza entre duas faixas rodoviárias (RS287 e RS509), onde os carroceiros transitam pelo acostamento provocando perigo de acidentes.

Os catadores carroceiros do bairro Camobi adaptamse às condições do trânsito e chegam mesmo a parar os veículos em horários de pico solicitando a sua travessia organizando-se em fileiras.

O trabalho cotidiano dos catadores representa um embate ao poder público, às empresas e à sociedade, numa relação de (in) visibilidade no mundo do trabalho, onde essas pessoas lutam pelos direitos de sua cidadania.

\subsection{Espaços e tempos de trabalho cotidiano dos catadores}

As famílias pesquisadas que realizam o trabalho de catação de material reciclável no bairro Camobi classificam-se como pessoas de uma classe social desfavorecida de meios básicos de vida, pois se supõe que a vida deve ser mantida em condições dignas com relação ao emprego e renda, moradia, alimentação, escola, saúde e transporte.

As famílias dos catadores são pessoas sem escolarização, onde se constatou $80 \%$ com ensino fundamental incompleto. Desses catadores, 59\% são mulheres entre 20 e 73 anos de idade, representando a realização de um trabalho de risco em vários sentidos, pois, com frequência essas mulheres são vistas com os seus filhos ou parentes menores de idade conduzindo as carroças de tração animal.

De forma breve, colocam-se alguns fatos que explicam a situação dos moradores da Vila Maringá, os quais foram deslocados a essa área na década de 1980, atendendo a política de retirada da população de áreas de risco (margens do arroio Cadena) e de ocupação irregular (bairro São José). O novo lugar passou a ser distante do Centro, local de trabalho, e também de não pertencimento a muitos deles que retornaram ao antigo lugar de vida.

Os espaços e tempos dos catadores entrevistados no bairro Camobi eram construídos por eles mesmos numa disputa pelos territórios do trabalho, ou seja, as ruas e locais de descarte do material reciclável. Na busca do material reciclável, alguns dos catadores percorrem distâncias que vão além de 20 quilômetros diários em tempos programados entre a coleta do lixo municipal. Os trabalhadores devem sair muito cedo de suas casas, pois desejam ter a sorte de encontrar o valioso material que possa lhes pertencer.

Os catadores disputam os espaços da cidade, do bairro, de forma desorganizada. O material é coletado por quem chegar primeiro ou daquele que conquistar a carisma do dono da casa ou do estabelecimento. Trata-se de uma relação de trabalho jogada a sorte e a solidariedade da população.

A concentração dos catadores nos diversos locais do bairro Camobi se estabelece pela quantidade de material descartado, citados pelos entrevistados como o Loteamento Santa Lúcia, o Loteamento Novo Horizonte, na área de concentração comercial da Faixa Velha e na Vila Santa Helena.

A partir da análise das entrevistas observou-se que um percentual de $59 \%$ do grupo pesquisado são mulheres, sendo $47 \%$ adultas em idade ativa, trabalhadoras e mães em média com cinco filhos. Os homens catadores, na maioria, também estavam na idade adulta. Mas é frequente a presença de crianças e jovens do sexo masculino na coleta do material acompanhadas ou sozinhas guiando as carroças. Também se tem a presença de pessoas 
idosas, homens e mulheres contradizendo ainda mais as condições de vida e sobrevivência dos pobres urbanos.

Alguns catadores entrevistados disseram que possuem residências ou locais de contato agendado para recolher o material que é separado a eles. Conheceu-se o caso de uma catadora, a denominada N. 03 de 56 anos, a qual trabalha há 20 anos nessa profissão na cidade de Santa Maria. No bairro Camobi, ela coleta diariamente nos fundos de um supermercado, onde o material é destinado somente a ela na condição de manter o local "limpo", como disse a funcionária responsável pelo depósito do supermercado. A referida catadora relata que, além do material reciclável, recebe a doação de alimentos descartados pelo supermercado complementando e mesmo suprindo a alimentação diária da sua família.

E para manter-se no domínio desse privilegiado local de descarte, a senhora catadora N.03 relatou possuir dois cavalos para fazer o transporte do material duas vezes por dia, manhã e tarde. Ela revelou ter cuidados com o animal e mesmo apego afetivo ao chamá-los pelos nomes. Contou que cuidou até o final da vida de um de seus cavalos, expressando saudosismo pelo animal que lhe servia.

Percebe-se que, no caso dessa catadora, existe um sentimento de apego ao trabalho adquirindo dele o seu sustento e o de sua família. Ela relatou com orgulho como trata sua família e disse ser importante o trabalho que realiza.

Em conversa com a catadora N.10, senhora de 73 anos, percebeu-se o gosto pelo trabalho de coleta quando disse que o dia em que não sai para a rua, como em dias de muita chuva, chega-lhe a dar dor de cabeça, por pensar que ficará em casa. Esse relato apropria-se de sentido, sendo que as pessoas encontram, em seu trabalho, o fazer, o ocupar-se de algo, o lugar da liberdade.

Outras mulheres, caso da catadora N.07 de 40 anos, filha da catadora N.03 e a filha da catadora N.10 de 73 anos, disseram que alimentam e vestem a família com o que ganham durante a coleta do material reciclável. Segundo a catadora N.03: "Quem cata ganha muita ajuda na rua". O marido da referida catadora N.10, de 75 anos, também é catador e coleta no bairro Centro de cidade com carroça a tração animal.

No sentido de ter o que fazer dessas pessoas ocupadas na coleta de materiais recicláveis, faz-se a reflexão desse tipo de trabalho no seu cotidiano. A catação é reconhecida como categoria profissional pela Classificação Brasileira de Ocupações, CBO, e diante da luta desses trabalhadores têm adquirido identidade. Há que se analisar também a Lei n.12.305/2010 da Política Nacional de Resíduos Sólidos (PNRS), que contempla 12 itens referentes ao trabalho dos catadores. E mais, a Lei n. 11.445/2007, permite a cooperativa de catadores prestar serviços. Ainda o Decreto n.5940/2006, estabelece que os catadores possam recolher material reciclável de órgãos públicos federais (PAULA, 2012, p.53).

A importância de trazer a legislação nessa discus- são deve-se ao poder de libertá-los de um sistema de opressão, enquanto exploração da força de trabalho e da vida dessas pessoas. São frequentemente pessoas que foram expropriadas dos meios de produção e de trabalho, restando-lhes buscar na catação um meio de trabalho livre. Mas que ainda lhes aprisiona pela dependência do atravessador ou da dificuldade de ir direto ao intermediário mais próximo da indústria de reciclagem.

O cotidiano do trabalho dos catadores exige-lhes apropriar-se de espaços e de tempos condizentes ao local/ horário do descarte do material reciclável. Há casos em que os catadores deixam seu telefone celular para aquele que irá descartar o material de modo que lhe chame. Os catadores são solicitados até mesmo para descartar tipos de materiais ou objetos como o caso de aparelhos de TV, de som, os quais são bens "inservíveis" (termo utilizado pela coleta seletiva para classificar materiais, definidos com aqueles que não têm destinação pública definida). Os catadores também são solicitados e pagos para descartar restos de materiais de construção, de jardinagem e mesmo corpos de animais domésticos. Essa realidade é comum em nosso meio e indica para o trabalho informal, onde os trabalhadores conseguem participar mesmo de modo ilegal do processo do capitalismo.

Para Canclini (2009, p.93):

Na América Latina, mas não só nela, é particularmente notável a desconexão encenada nos âmbitos da informalidade, em que se pode ter trabalho mas sem direitos sociais nem estabilidade, consegue-se vender, mas na rua, dirigir taxi sem autorização, produzir e comercializar discos e vídeos piratas, pertencer a redes ilegais, como as do narcotráfico e outras máfias que recrutam desempregados para tarefas discriminadas e desqualificadas (reciclagem de lixo, contrabando etc.).

O tempo passa rápido para os catadores, o trabalho cotidiano toma-lhes um tempo valioso e a sua força vital, pois precisam coletar o máximo de material e acumular o necessário para vender ao atravessador no final da semana, ou no final mês. Geralmente, a venda do material é feita semanalmente no valor médio $\mathrm{R} \$ 100,00$ (cem reais). A média mensal em vendas do material reciclável coletado alcança apenas $\mathrm{R} \$ 250,00$ (duzentos e cinqüenta reais). Alguns possuem maiores vínculos com o comprador, pois têm dívidas pelo empréstimo na compra do animal de tração, o cavalo ou a mesmo a carroça. Esses valores irão se somar a outras formas de aquisição da renda por outros membros da família e, também, a recursos provenientes de programas de governo como o Programa Bolsa Família ${ }^{7}$, benefício social

\footnotetext{
7 O Programa Bolsa Família é um programa de transferência direta de renda que beneficia famílias em situação de pobreza e de extrema pobreza em todo o País. O Bolsa Família integra o Plano Brasil Sem Miséria que tem como foco a atuação de 16 milhões de brasileiros com renda familiar per capita inferior a $\mathrm{R} \$ 70$ mensais e está baseado na garantia da renda, inclusão produtiva e no acesso aos serviços públicos. (Ministério do Desenvolvimento Social)
} 
dado a quase totalidade das famílias entrevistadas. De acordo com Lefebvre (1991, p.27)

“...essas pessoas nascem, vivem e morrem. Vivem bem ou mal. É no cotidiano que eles ganham ou deixam de ganhar a vida, num duplo sentido: não sobreviver ou sobreviver, apenas sobreviver ou viver plenamente. È no cotidiano que se tem prazer ou se sofre. Aqui e agora."

Aos catadores, "trabalhadores sobrantes", coletar material reciclável foi o que restou para sua sobrevivência. É uma forma de trabalho e renda desprovida de qualquer segurança e que no cotidiano requer a sua força vital.

\subsection{Os meios e instrumentos de trabalho e renda}

No que se refere aos meios e instrumentos de trabalho e renda dos catadores situam-se na discussão o tipo de transporte, riscos e periculosidade; manutenção e espaços de depósito do material; condições e riscos com os animais de tração.

Neste estudo de forma específica observou-se que vários catadores utilizam a área junto a sua moradia, como depósito do material reciclável além da carroça e o cavalo como se vê na figura 3 .

Dos trabalhadores entrevistados, $82 \%$ dos catadores utilizam a carroça com tração animal, e 18\% deles realizam a coleta com sua força física. Verificou-se que os $12 \%$ deles utilizam o carrinho de mão e $6 \%$ a catadora N.16, carrega no corpo. Esses altos índices de carroceiros refletem as longas distâncias necessárias para percorrer os lugares disponíveis para a coleta do material em relação a sua moradia.

O cotidiano do trabalho desses catadores, inclusive os entrevistados, vincula-se anteriormente a áreas centrais da cidade, pois grande parte deles moradia em área de ocupação irregular próxima ao bairro São José, relativamente mais próximo ao bairro Centro. E ao serem transferidos para a Vila Maringá, local mais distante do bairro Centro, eles enfrentaram dificuldades de deslocamento, encontrando nas carroças de tração animal a solução para carregar o material da coleta. Assim, o trabalho de coleta passa a ser realizado com esse meio, trazendo outros problemas recorrentes como a alimentação, doenças e sobrecarga no trato com os animais. Além disso, os catadores permanecem endividados numa relação de exploração da mais valia e de dependência junto aos atravessadores que negociam os meios e instrumentos de trabalho.

Mesmo os catadores da Vila Progresso e Beco do Beijo situam-se em lugares distantes das áreas de coleta, necessitando da aquisição da carroça com tração animal. Nesse local, encontrou-se um catador de 70 anos, que

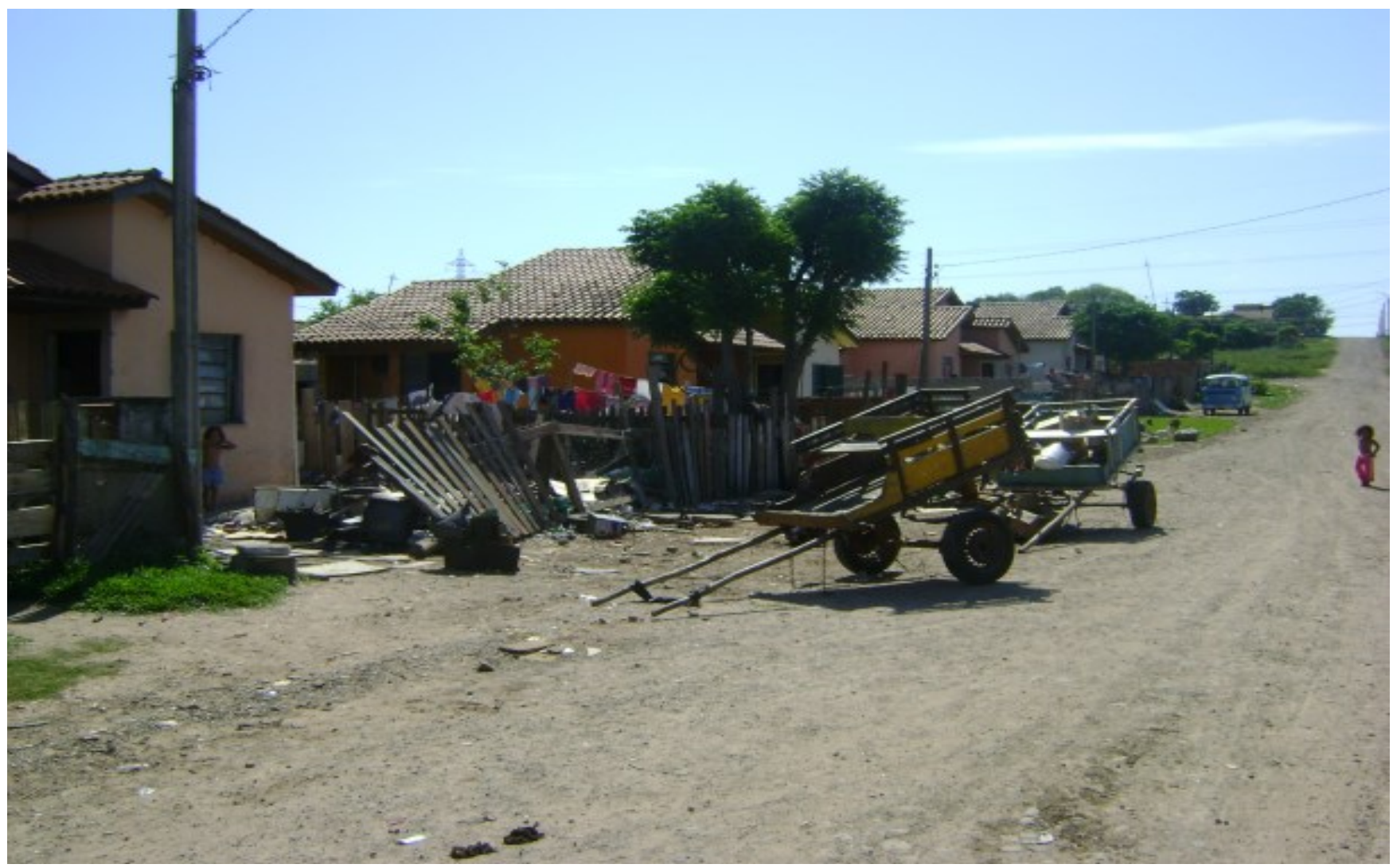

Figura 3 - Vista da Rua da Vila Maringá, onde se concentra a maioria dos catadores entrevistados. Fonte: Trabalho de campo, 2012. 
fazia a coleta com um pequeno carrinho de mão. Este possuía locais certos para fazer a coleta e ainda se tratava de um comprador intermediário de material reciclável com depósito em sua própria residência.

\footnotetext{
"No cotidiano estão contidas, além das adversidades que caracterizam a vida dos trabalhadores, as possibilidades de produzir uma vida nova: por trás da miséria dos trabalhadores esconde-se uma autêntica capacidade produtiva e criadora." (BARREIRA, 2009, p.72).
}

Observou-se a capacidade produtiva e criadora na disputa pelos espaços potenciais de produção dos resíduos sólidos, transformados em mercadoria à indústria de reciclagem. $\mathrm{O}$ autor citado tem base no pensamento da crítica da vida cotidiana de Lefebvre e se articula ao trabalho cotidiano dos catadores numa relação de trabalho e produção criativa.

\section{Considerações Finais}

Este estudo teve o objetivo de investigar e identificar os sujeitos envolvidos na atividade de coleta de materiais recicláveis da Vila Maringá na cidade de Santa Maria RS. Além disso, buscou-se a compreensão de como esses sujeitos agem e se reconhecem no trabalho e na vida cotidiana frente às adversidades e dificuldades inerentes à atividade de catador. Analisando os resultados, nota-se que o público alvo atingido pelo projeto reporta especificamente a grupos de pessoas com risco e vulnerabilidade no que tange às relações de trabalho e renda para dar condições de melhorias às suas precárias condições de vida.

Verificou-se a disputa pela territorialização na coleta do material pelo bairro Camobi, sem qualquer tipo de organização dos trabalhadores que não pertencem ou sequer conhecem alguma associação de separadores de material reciclável. São pessoas que trabalham sem segurança, direitos trabalhistas ou garantias na comercialização da mercadoria, onde quem designa o valor de troca é o intermediário.

Percebeu-se, também, que o trabalho das mulheres e o trabalho infantil são representativos, bem como a presença de idosos na atividade. Outra observação refere-se aos maus tratos com os animais, sendo importante um programa de ação para fiscalizar e assistir os animais e seus proprietários.

Existe nesse trabalho a exploração da força de trabalho do catador uma vez que a renda não complementa as mínimas necessidades da família. É uma atividade desgastante que se origina da ausência de trabalho, emprego e renda das famílias de classe baixa da sociedade. Desse modo, necessita-se de apoio efetivo das parcerias, tanto sob o ponto de vista material-estrutural, quanto para as ações de inserção social.

Esta pesquisa permitiu ainda, identificar as principais dificuldades e riscos que os trabalhadores enfrentam no dia a dia e, mesmo com a representação de uma minoria diante do número de trabalhadores da/na cidade de Santa Maria. Contudo, é necessário e urgente melhorar as condições de trabalho que garantam a cidadania frente à exclusão e desigualdade a que estão sendo submetidos.

Compreende-se também, que esses trabalhadores estão distantes da independência, tanto econômica, quanto social. Percebeu-se que por muito tempo, ainda, as políticas públicas assistenciais deverão ser um apoio importante na vida da maioria das pessoas entrevistadas.

Para esses sujeitos serem atores sociais precisarão lutar pelos seus direitos, pois para a sociedade capitalista eles continuarão anônimos, invisíveis, privados dos direitos mínimos. Estes trabalhadores acreditam que fazem um trabalho fundamental ao meio ambiente e a sociedade como um todo, mas não percebem que estão sendo privamos de seus direitos humanos, sociais e culturais.

É perceptível que a falta de informação aliada ao baixo nível de escolaridade, tornam a compreensão de seus direitos e a urgência em participarem de alguma associação ou cooperativa de reciclagem um início do que poderia vir a ser a conquista de melhores condições de vida.

Ao confrontar o referencial teórico estudado com a pesquisa realizada evidenciou-se que a diferença, a desigualdade e desconexão fazem parte do cotidiano dessas famílias e somente com educação de qualidade, serviço e assistência social será possível reduzir a desigualdade com que a sociedade trata esses trabalhadores.

O reconhecimento do projeto e das ações propostas tem sido aceitos parcialmente pelos catadores. No entanto, planejam-se estratégias e programas que possam realmente conscientizar os trabalhadores "sobrantes" a condições dignas de trabalho e de vida.

O projeto tem continuidade, e estão previstas parcerias junto com entidades. São programas e ações que exigem tempo necessário para alcançar efetivamente os objetivos do projeto. Desta forma, a previsão de futuras ações são as seguintes:

a) Preparação de reuniões e palestras que versam sobre as possibilidades de melhorias nas condições de vida dos trabalhadores na "catação" de material reciclável no que tange aos riscos e vulnerabilidade sociais, econômicas e ambientais, tem-se os temas a serem tratados:

As condições legais de viabilidade da atividade de catação pela exploração das relações de trabalho e comércio do material reciclável, em mercadoria, na base da indústria de reciclagem;

As condições de deslocamento para o trabalho nas ruas e rodovias, momento da coleta do material, em que o trabalhador usa a carroça com tração animal e mesmo humana;

As condições de manuseio do material coletado nas lixeiras pelos riscos à saúde e ferimentos; 
b) Criação de projetos e normatização da atividade via: Legalização do comércio do material reciclável a valores que compensam suas relações e meios de trabalho;

A possibilidade de criação de uma cooperativa de catadores, assim como uma usina de material reciclável,

Impulsionar a possibilidade de uma indústria de produtos feitos de material reciclável em Santa Maria;

Projetos alternativos de trabalho e renda, além da coleta do material reciclável nas ruas.

A relevância da proposta de ações extensionistas foi a de estabelecer parcerias junto a programas institucionais para auxiliar na organização dos trabalhadores em termos de relações de trabalho, emprego e renda e assistência social.

O reconhecimento e a legitimação do poder público à atividade são fundamentais. Por fim, para que os catadores sejam vistos enquanto atores econômicos se faz necessário receberem inicialmente suporte e assistência, no sentido de organizá-los numa associação ou cooperativa. Pois, o grupo sozinho não conseguirá visualizar mudanças assim como estratégias que possibilitem melhores condições de vida.

\section{Referências}

Associação Brasileira de Empresas de Limpeza pública e Resíduos Especiais - Abrelpe. Panorama dos resíduos sólidos no Brasil. Disponível em: http://www.abrelpe.org.br/biblioteca_artigos.cfm. Acesso em: 10/5/2013.

BARREIRA, M. R. A. Henri Lefebvre: a crítica da vida cotidiana na experiência da modernidade. Tese (Doutorado) UERJ, Instituto de Psicologia. 2009.

BESEN, G. R. Gestão sustentável de resíduos sólidos na região metropolitana de São Paulo. In: Resíduos sólidos urbanos e seus impactos socioambientais. SANTOS, M. C. L. dos e GONÇALVES-DIAS, S. L. F (orgs.). São Paulo: IEE-USP, 2012

BURGOS, R. Periferias Urbanas da Metrópole de São Paulo: territórios da base da indústria da reciclagem no urbano periférico. Geografia Humana, USP, (Tese de Doutorado), São Paulo, 2008.

CALDERONI, Sabetai. Os bilhões perdidos no lixo. 4. ed. São Paulo: Humanitas/ FELCH/USP, 2003.

CANCLINI, N. G. Diferentes, Desiguais e Desconectados - mapas da interculturalidade; trad. LUIZ Sérgio Henriques. - 3.ed. - Rio de Janeiro: UFRJ, 2009.
COOPER, DONALD R. Métodos de pesquisa./ Donald R. Cooper e Pamela S. Shindler; trad. Luciana de Oliveira da Rocha. - 7ª Ed. - Porto Alegre: Bookman, 2003.

DALLARI, D. A. Constituição e constituinte. São Paulo. Saraiva, 1998.

DIAS, Sônia Maria. Gestão de resíduos sólidos. Catadores, participação e cidadania - novas articulações? Working Paper WIEGO (Políticas Urbanas), nº 18, p. 1-22, 2010.

GODOY, ARILDA S. Introdução à pesquisa qualitativa e suas possibilidades, In Revista de Administração de Empresas, V.35, n.2, Mar./abr. 1995a , p.57-63. Disponível em http://www.planalto. gov.br. Acesso em 01 de dezembro de 2013.

HELLER, A. Sociología de La vida cotidiana. 3a․ ed. Barcelona, Ediconaes Península, 1991.

---. O cotidiano e a história. 7ª . ed. São Paulo, Paz e Terra, 2004.

INSTITUTO BRASILEIRO DE GEOGRAFIA E ESTATÍSTICA - Censo Demográfico. Disponível em: http://www.planalto.gov.br/ccivil_03/ constituicao/constituicao.htm. Acesso em: 15/11/2013.

INSTITUTO BRASILEIRO DE GEOGRAFIA E ESTATÍSTICA - Conceitos Principais. Disponível em: http://www.ibge.gov.br. Acesso em: 24/1/2014

LEAL, A. C. et alli. A reinserção do lixo na sociedade do capital: uma contribuição ao entendimento do trabalho na catação e na reciclagem. Revista Terra Livre, Presidente Prudente, v. 18, n. 19, pp. 177-190, 2003.

LEFEBVRE, H. A vida cotidiana no mundo moderno. São Paulo, Ática, 1991.

LOGAREZZI, A. Contribuições conceituais para gerenciamento de resíduos sólidos e ações de educação ambiental. In: LEAL, A. C. Resíduos sólidos no Pontal do Paranapanema. Presidente Prudente (SP): Ed. Antônio Thomaz Júnior, 2004.

MDS- Ministério do Desenvolvimento Social e Combate à Fome. O Programa Bolsa Família. Disponível em http://www.mds.gov.br/ bolsafamilia. Acesso em 12 de novembro de 2013.

MATOS, Patrícia F.; PESSÔA, Vera L. S. Observação e entrevista: construção de dados para a pesquisa qualitativa em geografia agrária. In: RAMIRES, 
Julio C. de L.; PESSÕA, Vera L. S (Org.). Geografia e pesquisa qualitativa: nas trilhas da investigação. Uberlândia: Assis Editora, 2009. p. 279-291.

Movimento Nacional dos catadores de materiais recicláveis. De Catador para Catador. Circulação na Região Sul do Brasil - Ano I - número 1 - outubro/ novembro de 2009 - disponível em: www.mncr. org.br

NOBRE, N. Proposta Regulamenta Profissões de Catador e Reciclador de papel. Reportagem editada em 04/06/2010. Câmara dos Deputados. Disponível em: http://www2.camara.leg.br. Acesso em: 20/11/2013.

PAULA, E. A história da COOPAMARE: dificuldades, lutas e conquistas dos catadores, In: Resíduos sólidos urbanos e seus impactos socioambientais SANTOS, M. C. L. dos e GONÇALVES-DIAS, S. L. F (orgs.). São Paulo: IEE-USP, 2012.

PREFEITURA MUNICIPAL DE SANTA MARIA. Disponível em: http://www.santamaria.rs.gov.br/ Acessado em: 10/09/2013.

Projeto de Lei PLS 279/2011. Senado Federal. Aprovada inclusão de catadores como segurados especiais da previdência. Portal de notícias. Disponível em:

http://www12.senado.gov.br/noticias Acesso em: $10 / 12 / 2013$

RODRIGUES, A. M. Produção e Consumo do e no Espaço - Problemática Ambiental Urbana. São Paulo: Hucitec, 1998.

SANTOS, I. J. dos. Determinantes dos rendimentos de catadores de materiais recicláveis no Brasil: uma abordagem a partir dos microdados da amostra do censo IBGE 2010. Revista Pegada - vol. 14, n.1, pp 298-329, Julho/2013.

SANTOS, M., Por Uma Outra Globalização - do pensamento único á consciência universal. 6. ed. Rio de Janeiro - São Paulo: Record, 2001.

SANTOS, M., A Natureza do Espaço: Técnica e Tempo, Razão e Emoção. São Paulo: Ed. Da Universidade de São Paulo, 2008.

VILHAÇA, F. Espaço Intra-urbano no Brasil. São Paulo: Studio Nobel: FAPESP: Lincoln Institute, 1998. 